\title{
EXTENSÃO UNIVERSITÁRIA E INCLUSÃO SOCIAL DE ESTUDANTES DO ENSINO MÉDIO PÚBLICO
}

\author{
UNIVERSITY EXTENSION AND THE SOCIAL INCLUSION OF PUBLIC HIGH SCHOOL STUDENTS
}

\author{
EXTENSIÓN UNIVERSITARIA E INCLUSIÓN SOCIAL DE ESTUDIANTES \\ DE LA ENSEÑANZA MEDIA PÚBLICA
}

\author{
Liliane Lins ${ }^{1}$ \\ Mayala Moura Valença de Oliveira ${ }^{2}$ \\ Ana Carolina Esteves Cattony ${ }^{3}$ \\ Carla Reale Batista ${ }^{4}$ \\ Patrícia Dias Schmitz ${ }^{5}$ \\ André Luiz Peixoto ${ }^{6}$ \\ Thaís de Lira Caracas ${ }^{7}$
}

Resumo A extensão universitária no processo educativo permite a elaboração da práxis e do conhecimento científico por meio de ações na comunidade, gerando um processo sistematizado de troca de saberes. Este estudo avaliou as intervenções educativas do ensino superior privado no ensino médio público aplicadas às áreas de ciências e prevenção em saúde, realizadas no período de fevereiro de 2005 a novembro de 2008 . A intervenção capacitou vinte estudantes do ensino médio e realizou o Dia de Saúde do Jovem, com participação de 362 estudantes de Salvador, Bahia. Questionários anônimos foram preenchidos antes e depois de cada seminário e oficina, contendo questões sobre o tema abordado nas atividades. Observou-se a importância da intervenção do ensino superior privado na qualificação de estudantes do ensino médio da rede pública. O ensino superior privado pode participar da inclusão social, qualificando indivíduos para ingressarem no processo de formação profissional de forma mais atenta à dinâmica social. O grande desafio para o ensino superior da área da saúde continua sendo reconceituar o seu papel ativo na educação e na prevenção em saúde, com participação efetiva de acadêmicos, cientistas e educadores.

Palavras-chave extensão; ensino público; universidade; educação médica.
Abstract University extension in the educational process allows for the preparation of the praxis and scientific knowledge through actions in the community, generating a systematic process of knowledge exchange. This study evaluated the educational interventions of private higher education in public high school applied to the areas of sciences and prevention in health, conducted from February 2005 to November 2008. The intervention trained 20 high school students, and held the Youth Health Day, attended by 362 students from Salvador, Brazil. Anonymous questionnaires containing questions about the subject's activities were completed before and after each seminar and workshop. The importance of the intervention of private higher education in the training of public high school students was noted. Private higher education can participate in social inclusion, qualifying individuals to join the professional training process in a manner more attentive to the social dynamics. The challenge for higher education in the health field remains reconceptualizing its active role in health education and prevention, with the effective participation of academics, scientists, and educators.

Keywords extension; public education; university; medical education. 


\section{Introdução}

Os projetos de extensão universitária, além de tornarem possível a construção de um conhecimento acadêmico mais elaborado, possibilitam a democratização do saber e a participação da comunidade no ambiente científico. Essas ações universitárias permitem a troca de saberes entre sociedade e universidade. Segundo o Plano Nacional de Extensão Universitária (Brasil, 2000/2001), o ensino superior deve integrar atividades educativas, culturais e científicas que englobem educação e pesquisa para um melhor desenvolvimento da comunidade e uma otimização da formação profissional universitária. Essa integração permite a produção do conhecimento a partir do confronto com a realidade brasileira e regional, a democratização do saber acadêmico e a participação efetiva da comunidade na universidade (Saraiva, 2007).

A educação é um dos pilares fundamentais para o desenvolvimento socioeconômico individual e coletivo. Há algumas décadas, o Brasil vem enfrentando a dura realidade do declínio de seu sistema público de ensino. A escola pública, antes referência de qualidade, foi gradativamente perdendo espaço para a rede de ensino particular. Tal situação gerou uma estrutura similar à pirâmide social do país, com as classes sociais de menor poder aquisitivo compondo os planos mais baixos de escolaridade, devido à impossibilidade de acesso à educação privada. Dessa forma, as desigualdades sociais tornaram-se alarmantes e têm dificultado o acesso de muitos jovens à universidade (Ferreira, 2005; Souza et al., 2004). Nesse contexto, a educação superior não pode ser omissa no processo de formação dos cidadãos e deve trabalhar conceitos de comprometimento e solidariedade em busca de uma sociedade mais justa e igualitária. No que tange à educação em saúde, o processo de ampliação do ensino médico para a realidade da comunidade permite ao estudante de medicina a vivência com problemas reais nas atividades de extensão, possibilitando a articulação entre a teoria e a prática na busca da alteridade e humanização do próprio estudante (Ponte et al., 2009).

O declínio do ensino público reflete-se também na educação em saúde, como por exemplo na prevenção de gravidez na adolescência e em doenças sexualmente transmissíveis (DSTs). O baixo nível de informação sobre a prevenção de determinadas doenças, como as sexualmente transmissíveis, faz com que indivíduos sejam acometidos por elas, acarretando problemas à saúde pública e a persistência da reprodução das desigualdades sociais (Martins et al. , 2006). Foi nesse contexto que o Núcleo de Estudo e Pesquisa em Embriologia (Nepe) criou o Projeto de Extensão Universitária A Escola Dentro da Universidade, que abriu portas da instituição à comunidade, permitindo ao estudante de ensino médio a construção de conhecimentos para 
prevenção de DSTs e gravidez na adolescência, tornando-os multiplicadores do saber em seu entorno. O projeto visou à criação de um espaço de prática e transferência de conhecimentos, interferindo na formação de futuros profissionais, de forma que estes possam identificar as vulnerabilidades da população sobre a qual irão interagir, desenvolvendo o discernimento para a redução das desigualdades na atenção à saúde.

O trabalho aqui tratado buscou avaliar as ações do Projeto Escola Dentro da Universidade em estudantes do ensino médio público e em estudantes de medicina da Escola Bahiana de Medicina e Saúde Pública (EBMSP), em Salvador, Bahia.

\section{Materiais e métodos}

Um estudo retrospectivo avaliou as intervenções do Projeto de Extensão A Escola Dentro da Universidade, realizadas no período de fevereiro de 2005 a novembro de 2008. Essas atividades foram desenvolvidas com estudantes da EBMSP e de um colégio do ensino médio em Salvador, Bahia.

O projeto foi dividido em duas etapas, a primeira constituída pela capacitação de vinte estudantes do ensino médio, e a segunda pela realização do Dia de Saúde do Jovem, com a participação de 362 estudantes.

A instituição de ensino médio que participou do projeto foi o Colégio Estadual Severino Vieira, localizado em Salvador, selecionado por critérios de proximidade à instituição universitária, o que facilitava o acesso dos alunos e amenizava custos com transporte. Na primeira etapa, a diretoria foi contatada, ficando responsável por selecionar vinte alunos do ensino médio: dez do $2^{\circ}$ ano e dez do $3^{\circ}$ ano, por critérios de livre decisão de participação.

Durante essa fase do projeto, foram feitas visitas semanais à EBMSP em um período de dez meses e realizados seminários e oficinas sobre os temas pesquisa, DST, gravidez precoce, métodos contraceptivos, desenvolvimento humano, teratógenos e primeiros socorros. Os seminários foram ministrados por acadêmicos de medicina da EBMSP, integrantes do Nepe, que receberam treinamento do professor responsável, estando este presente na execução de todas as atividades. Em alguns encontros houve atividades práticas subsequentes ao seminário, como visitas ao biotério, prática sobre o manejo de animais experimentais, observação de fetos e realização de pesquisas no laboratório de informática, entre outras. Os participantes também fizeram um estágio em técnica laboratorial com duração de três semanas, no qual tiveram práticas de histologia e aprenderam sobre o processamento de lâminas histológicas. Todas as normas de biossegurança foram seguidas, garantido o bem-estar dos participantes. 
Essa fase da intervenção foi avaliada por meio de questionários anônimos, preenchidos antes e depois de cada seminário, contendo questões sobre o tema abordado nas atividades. Foram confeccionados dez questionários de vinte perguntas sobre cada tema e atividade descrita anteriormente. Os dados foram analisados estatisticamente no programa EPI-Info 3.5.1.

No fim da primeira etapa, os dez alunos do $2^{\circ}$ ano concorreram a cinco bolsas do Conselho Nacional de Pesquisa e Desenvolvimento Científico e Tecnológico e da Fundação de Amparo à Pesquisa do Estado da Bahia (CNPq/Fapesb). Os alunos aprovados passaram a desenvolver atividades educativas, vinculadas ao projeto Escola Dentro da Universidade, tornando-se agentes multiplicadores do conhecimento em seu entorno, dando início à segunda etapa do projeto. Juntamente com os estudantes de medicina, os cinco bolsistas realizaram vários encontros, denominados Dia de Saúde do Jovem, com outros alunos de escolas públicas que cursavam o $2^{\circ}$ e o $3^{\circ}$ anos do ensino médio. A referida atividade consistiu em um dia de palestras e oficinas sobre prevenção de DSTs, métodos contraceptivos, teratogênese e primeiros socorros. Ao todo, 362 estudantes da escola pública participaram do Dia de Saúde do Jovem e preencheram questionários anônimos, semelhantes aos preenchidos pelos participantes do Projeto de Extensão A Escola Dentro da Universidade, antes e depois das atividades realizadas.

O estudo foi aprovado pelo Comitê de Ética em Pesquisa da Escola Bahiana de Medicina e Saúde Pública (CEP/EBMSP), de acordo com os termos da resolução n. 196/96, sob o número 023/2011.

\section{Resultados}

Na primeira etapa do projeto, realizada com os vinte alunos selecionados, observou-se que 77,8\% nunca haviam tido acesso a um laboratório de ciências. Aqueles que tiveram a oportunidade de trabalhar em um laboratório o fizeram fora do ambiente escolar. Foi constatado que 33,3\% desses alunos de ensino médio não tinham conhecimento sobre o que significava biossegurança. No entanto, por meio das atividades práticas e teóricas, esse resultado foi modificado, demonstrando que $100 \%$ dos discentes aprenderam o conceito e a utilização dos itens de segurança em um laboratório (Tabela 1). 
Tabela 1

\begin{tabular}{lcc}
\multicolumn{3}{l}{$\begin{array}{l}\text { Percentagem de alunos do ensino médio que identificaram itens de } \\
\text { relevância para a segurança pessoal nos laboratórios. }(\mathrm{n}=20)\end{array}$} \\
\hline Item & $\begin{array}{c}\text { Antes das atividades } \\
(\%)\end{array}$ & $\begin{array}{c}\text { Após as atividades } \\
\text { (\%) }\end{array}$ \\
\hline Chuveiro & 0,0 & 100,0 \\
Jaleco & 83,0 & 100,0 \\
Luvas & 100,0 & 100,0 \\
Óculos & 44,4 & 100,0 \\
Máscara & 94,4 & 100,0 \\
Torneira & 16,7 & 100,0 \\
Sapato fechado & 83,3 & 100,0 \\
Pró-pé & 5,6 & 100,0 \\
Prendedor de cabelo & 50,0 & 72,2 \\
Ar-condicionado & 38,9 & 72,2 \\
\hline
\end{tabular}

Fonte: Os autores.

Metade dos estudantes não sabia da necessidade de procedimentos eficazes de lavagem das mãos em um laboratório, resultado convertido ao final das atividades educativas para $100 \%$ dos indivíduos submetidos ao questionário. Apesar de a maioria $(94,4 \%)$ apresentar conhecimento da necessidade de se manter uma postura diferenciada no ambiente laboratorial, $27,8 \%$ acreditavam que esta necessidade se dava por uma questão de educação e $11,1 \%$ por respeito ao profissional que os acompanhava. Esta situação se alterou, passando $100 \%$ dos estudantes a apontarem a prevenção de acidentes como fator determinante na manutenção de uma postura adequada no laboratório.

Um terço $(33,3 \%)$ dos alunos informou que não sabiam o que significava ética. Esse resultado foi convertido para $100 \%$ ao final do projeto. Dentre o grupo estudado, 22,2\% sabiam o que era um biotério antes do início das atividades, e ao término destas, todos tiveram a oportunidade de conhecer o ambiente e manusear animais. Os estudantes obtiveram ainda conhecimento de quais animais podem ser utilizados em pesquisa científica (Tabela 2). Todos os alunos demonstraram vontade de aprender mais sobre os animais experimentais; relataram que esse tipo de pesquisa era imprescindível para aquisição do conhecimento científico e que almejavam participar de outros projetos semelhantes. 
Tabela 2

\begin{tabular}{lcc}
\multicolumn{3}{l}{$\begin{array}{l}\text { Percentagem de alunos do ensino médio que identificaram animais que } \\
\text { poderiam ser utilizados como cobaias. }(\mathrm{n}=20)\end{array}$} \\
\hline Item & $\begin{array}{c}\text { Antes das atividades } \\
(\%)\end{array}$ & $\begin{array}{c}\text { Antes das atividades } \\
(\%)\end{array}$ \\
\hline Cavalo & 16,7 & 77,8 \\
Gato & 0,0 & 55,6 \\
Rato & 100,0 & 100,0 \\
Coelho & 61,1 & 94,4 \\
Cachorro & 0,0 & 61,1 \\
Sapo & 33,3 & 94,4 \\
Porco & 11,0 & 88,9 \\
Ave & 83,3 & 50,0 \\
Hamster & 50,0 & 83,3 \\
Rã & 66,7 & 100,0 \\
\hline
\end{tabular}

Fonte: Os autores.

Com relação às DSTs, 7,7\% dos alunos não souberam identificar que herpes e sífilis se enquadram nesta categoria de doenças. Já para a hepatite B, $38,5 \%$ não sabiam do seu caráter de transmissão sexual. Estes resultados foram convertidos para $100 \%$ no segundo questionário. Além disso, 100,0\% dos participantes demonstraram ter adquirido conhecimentos acerca dos meios de contaminação por DST: pela prática sexual sem preservativo, pela utilização de drogas injetáveis através de seringas compartilhadas e por transfusão sanguínea.

Os acadêmicos de escola pública aumentaram seus conhecimentos sobre fatores para a prevenção das DSTs: a diminuição no número de parceiros e a presença de sinais (corrimento, verrugas e bolhas e eritema na genitália e região oral) dessas doenças em seus parceiros como fatores importantes para se prevenir (de $46,2 \%$ para $53,8 \%$ e de $23,1 \%$ para $61,5 \%$, respectivamente). Alguns desses resultados podem ser observados na Tabela 3.

Tabela 3

$\begin{aligned} & \text { Percentagem de alunos do ensino médio que caracterizaram algumas DSTs por meio de seus } \\
& \text { respectivos sinais e sintomas. }(\mathrm{n}=20)\end{aligned}$
\begin{tabular}{lcc} 
Afirmação/Patologia & $\begin{array}{c}\text { Antes das atividades } \\
\%\end{array}$ & $\begin{array}{c}\text { Após as atividades } \\
\%\end{array}$ \\
\hline $\begin{array}{l}\text { Infecção de células hepáticas, podendo causar } \\
\text { Câncer de fígado/hepatite B }\end{array}$ & 61,5 & 76,9 \\
\end{tabular}


Continuação - Tabela 3

Percentagem de alunos do ensino médio que caracterizaram algumas DSTs por meio de seus respectivos sinais e sintomas. $(n=20)$

\begin{tabular}{lcc}
\hline Afirmação/Patologia & $\begin{array}{c}\text { Antes das atividades } \\
\%\end{array}$ & $\begin{array}{c}\text { Após as atividades } \\
\%\end{array}$ \\
\hline $\begin{array}{l}\text { Doença infectocontagiosa caracterizada por } \\
\text { corrimento purulento que sai da uretra, produz } \\
\text { coceira e ardência ao urinar/gonorreia }\end{array}$ & 38,5 & 69,2 \\
$\begin{array}{l}\text { Feridas redondas que não causam dor, de } \\
\text { superfície limpa e firme, atingem todos os órgãos } \\
\text { e podem infectar o feto na gestação/sífilis }\end{array}$ & 15,4 & 53,8 \\
$\begin{array}{l}\text { Caracteriza-se por lesões verrucosas/HPV } \\
\text { Pode causar câncer de colo de útero em }\end{array}$ & 61,5 & 84,6 \\
mulheres/HPV & 53,8 & 92,3 \\
\hline
\end{tabular}

Fonte: Os autores.

DSTs: Doenças sexualmente transmissíveis; HPV: Sigla em inglês de Human Papiloma Virus; em português, vírus do papiloma humano.

O conhecimento dos estudantes de que agentes infecciosos podem causar anomalias de desenvolvimento embrionário e fetal aumentou de $18,2 \%$ para $81,2 \%$, após as ações educativas do projeto.

As consequências do uso de drogas lícitas pela gestante, como anomalias de desenvolvimento, distúrbios funcionais, morte intrauterina e retardo do crescimento fetal, foram reconhecidas pela maioria dos estudantes $(90,9 \%, 63,6 \%$, $81,8 \%$ e 90,9\%, respectivamente); porém, na segunda etapa do questionário, $100 \%$ demonstraram esse conhecimento. O Gráfico 1 demonstra a identificação de algumas drogas pelos participantes como potenciais teratógenos químicos.

Gráfico 1

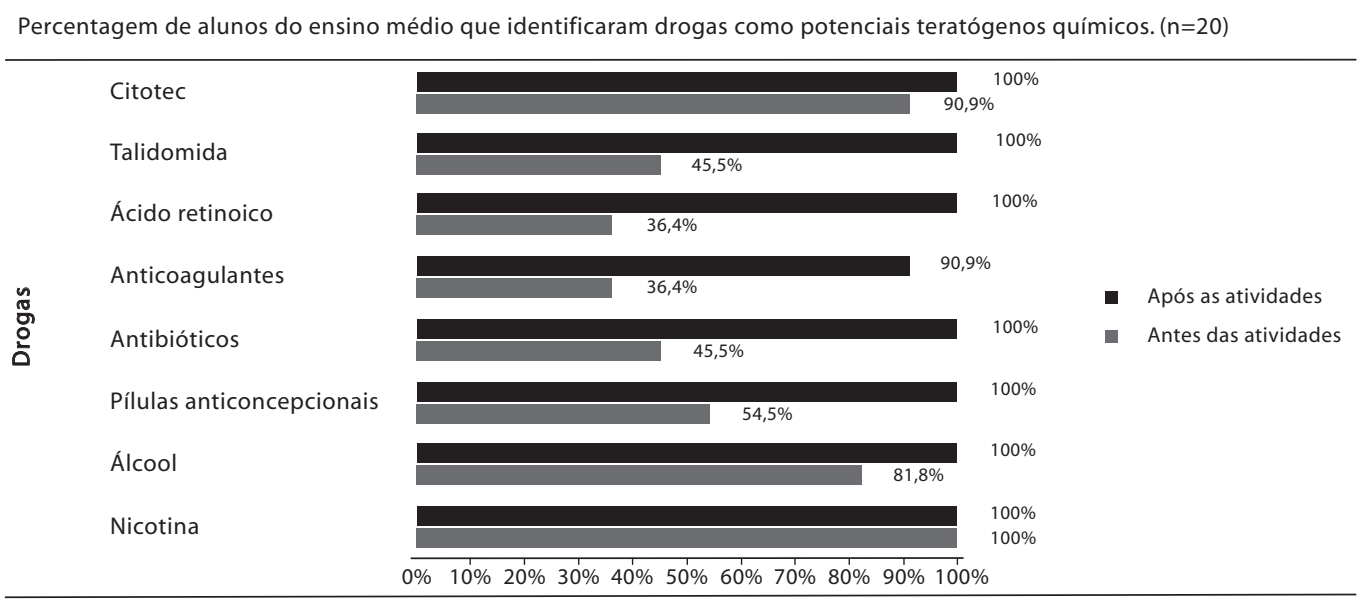

Fonte: Os autores. 
Dos vinte alunos inquiridos, 53,8\% sabiam o que eram agentes biológicos, dado que foi revertido para $100 \%$. Apenas $46,2 \%$ acreditavam ser possível um feto contrair herpes da mãe durante a gestação, índice modificado para $100 \%$ após os trabalhos. A respeito da toxoplasmose, 7,7\% confirmaram saber o que era a doença, enquanto no segundo questionário todos demonstraram tomar conhecimento da doença e de seu agente causador. É importante ressaltar que nenhum dos acadêmicos tinha conhecimento da forma de contaminação pelo Toxoplasma gondii, dado este revertido para $100 \%$ que apontaram o contato com cães e gatos como forma mais prevalente de infecção.

Outra expressiva diferença observada no conhecimento foi sobre a necessidade da utilização de drogas antirretrovirais durante a gravidez para evitar a contaminação do feto pelo HIV, assim como a ação teratogênica do citomegalovírus, passando de $46,2 \%$ a $84,6 \%$ e de $30,8 \%$ a $100 \%$, respectivamente. Ainda sobre teratógenos, todos os alunos expressaram a vontade de ter mais informações sobre este tema e afirmaram não ter acesso a tal tipo de conhecimento na sua escola de origem.

Em relação ao Dia de Saúde do Jovem, os estudantes bolsistas do ensino médio ministraram as oficinas como agentes multiplicadores do saber a 362 alunos do ensino médio público. Antes das atividades, somente $26 \%$ desses alunos reconheceram a hepatite B como DST; após as atividades, 97\% passaram a reconhecê-la como doença sexualmente transmissível. A maioria dos alunos já sabia identificar gonorreia (86\%) e HPV (87\%) como DSTs antes das atividades; após a intervenção, os dados converteram-se para 100\%. Em relação à sífilis, os alunos mostraram-se informados, demonstrando unanimidade $(100,0 \%)$ no reconhecimento da patologia antes e depois das atividades. No módulo de primeiros socorros, 93\% sinalizariam a via em caso de acidente de trânsito, antes das atividades, e 100,0\% após. Antes, 76\% não dariam água para tranquilizar a vítima; após as atividades, esse número converteu-se em $97 \%$.

No que tange ao desenvolvimento fetal e ao efeito de drogas lícitas, antes das atividades $35 \%$ sabiam que o cigarro é uma droga com potencial teratogênico; após as atividades, os dados se converteram para $92 \%$. Somente 33\% sabiam que o álcool é teratógeno; após a palestra, 95\% dos alunos passaram a reconhecer o potencial teratógeno da droga. Apenas $13 \%$ dos alunos reconheciam os efeitos teratógenos dos contraceptivos orais, antes das atividades; após, 95\% passaram a reconhecê-los.

Os cinco bolsistas de iniciação científica júnior $\mathrm{CNPq} /$ Fapesb relataram que a experiência foi bastante produtiva e permitiu a aquisição de novos conhecimentos acerca da temática abordada. Para alguns, as atividades foram importantes para a superação da timidez e do medo de falar em público, tornando-os mais comunicativos. Além disso, o projeto proporcionou con- 
tato com diversos públicos, o que foi importante para o crescimento pessoal de cada um. O contato dos bolsistas com os estudantes de medicina representou um incentivo para ingressar na faculdade e despertou a curiosidade e a vontade de conhecer a área da saúde. Os estudantes bolsistas relataram que os seus professores aprovaram as atividades desenvolvidas, incentivando-os ao exercício de atividades de liderança na própria escola e a participarem cada vez mais de projetos semelhantes. Os docentes do ensino médio passaram a discutir com eles os assuntos pesquisados e desenvolvidos durante o projeto.

Os estudantes de medicina que interagiram diretamente com os bolsistas do ensino médio referiram que a intervenção proporcionou amadurecimento pessoal e aprofundamento dos conhecimentos abordados. Mais do que isso, o projeto possibilitou o contato com uma realidade diferente daquela a que estavam acostumados, pois se depararam com diferenças socioeconômicas e outras dificuldades, incluindo o acesso à educação de qualidade. Esse fato proporcionou a aproximação com diferentes classes sociais, o que os auxiliará futuramente no exercício da medicina. De acordo com o relato dos estudantes do ensino superior, esse trabalho foi importante na sua formação, uma vez que, até então, a focalização acadêmica se dava em torno do corpo, de patógenos e das doenças. No entanto, nesse projeto, o foco de aprendizagem passou a ser o estudante adolescente que ainda não adoeceu, privilegiando-se as medidas promocionais e preventivas. Além disso, eles se dedicaram a transmitir parte do conhecimento que adquiriram na faculdade a pessoas que ainda não ingressaram no ensino superior, agindo diretamente na comunidade, transformando-a e tornando seus integrantes multiplicadores do saber.

\section{Discussão}

Observou-se que os estudantes de ensino médio que participaram da primeira fase do projeto obtiveram excelente desempenho no decorrer dos trabalhos. Foram assíduos e participativos em todas as suas etapas, apresentando notável evolução cognitiva nas avaliações teórico-práticas. Estes achados vêm ratificar a teoria defendida por Sousa e colaboradores (2004) de que o estudante não se interessa por ciência devido à inacessibilidade ou à falta de oportunidade de vivenciá-la. Como sugere Ferreira (2005), a melhoria do ensino público não é somente consequência do processo de aperfeiçoamento da escola e dos mestres, mas da adoção de diretrizes políticas que formem um conjunto de planos e ações educacionais complexas. Nesse sentindo, a extensão universitária pode representar uma dessas ações educacionais que propiciam o avanço da educação brasileira no âmbito das ciências e da tecnologia, contando com a participação de educadores, cientistas e comunidade. 
Outro aspecto observado foi a falta de estrutura da escola pública como fator limitante para o crescimento socioeducacional do aluno na introdução de discussões acerca de temas relacionados à ciência, como as questões éticas, biossegurança e pensamento científico. Corroborando essa linha de pensamento, tem-se o exemplo de que a maioria $(77,8 \%)$ dos alunos não teve oportunidade anterior ao projeto de praticar atividades laboratoriais, embora exista um laboratório na instituição escolar. Vale ressaltar que aqueles que tiveram oportunidade de realizar práticas laboratoriais as realizaram fora das dependências da escola. No entanto, torna-se importante salientar que atualmente o Centro Estadual de Educação Profissional Severino Vieira, antiga Escola Estadual Severino Vieira, está passando por uma reforma no ensino, substituindo o ensino médio pelo ensino profissionalizante, que pode ser mais efetivo no sentido de promover o contato dos estudantes com laboratórios práticos.

A vontade de participar do projeto, exibida pelos estudantes de ensino médio, revelou uma carência por parte deles no acesso a programas semelhantes na escola, sobressaindo a importância da extensão universitária na comunidade. Acredita-se que essas atividades propiciam a formação de agentes multiplicadores que transferirão conhecimentos à sua comunidade de maneira eficiente. Reafirma-se, então, o pensamento de Sousa e colaboradores (2004) sobre o papel de divulgador do pesquisador e a relevância da extensão universitária nesse processo. Evidenciou-se o êxito dos alunos bolsistas de iniciação científica Júnior CNPq/Fapesb como agentes multiplicadores do conhecimento durante as atividades do Dia de Saúde do Jovem, quando demonstraram bom nível de aprendizado após a atividade.

Temas como DST, prevenção da gravidez ou mesmo os riscos inerentes a uma gestação são pouco abordados na escola, como relatado pela totalidade dos alunos da amostra selecionada. Considerando o contexto atual, é importante que a escola construa com os alunos o conhecimento sobre as DSTs e saúde reprodutiva como uma urgência social no contexto do ensino fundamental e médio (Martins et al., 2006; Brêtas et al., 2009). Temas dessa natureza vêm sendo estabelecidos em decorrência das necessidades emergenciais da sociedade que, atualmente, ressente-se de um envolvimento maior das diversas áreas sociais com o problema. Isto reforça mais uma vez a importância de se expandirem os conhecimentos no meio acadêmico, ajudando a promover saúde e tendo um impacto mais profundo no tocante à prevenção das questões de saúde pública.

Segundo a pesquisa de Martins e colaboradores (2006), o nível de conhecimento adequado sobre métodos anticoncepcionais de adolescentes é baixo e tem associação com variáveis socioeconômicas, sugerindo que os jovens que possuem melhores condições sociais têm acesso a informações de melhor qualidade e, consequentemente, mais conhecimento. Cabe salientar que o 
elevado nível de conhecimento de métodos anticoncepcionais não está relacionado ao seu uso mais frequente ou correto (Almeida et al., 2003), o que ressalta a importância de atividades educativas na temática nesse projeto de extensão.

A gravidez na adolescência é assunto cada vez mais presente no cotidiano dos estudantes. Ela ocorre, na maioria das vezes, em momentos de indefinição, indecisão e, sobretudo, falta de conhecimento sobre educação sexual, sexualidade e planejamento familiar. Esse fator reflete não somente a falta de universalização da qualidade de ensino, como bem explicitou Sousa e colaboradores (2004), mas também a falta de equidade e abrangência do sistema de saúde brasileiro. Nessas circunstâncias, o espaço escolar torna-se cada vez mais importante, pois é fundamental seu engajamento na discussão desse tema. Assim buscar-se-á, em conjunto com a comunidade, especialmente com os pais, desenvolver de forma coletiva programas e projetos comprometidos com o bem-estar e a saúde da população escolar.

De acordo com Guimarães, Ferreira e Villaça (2008), a extensão em sua interface com as comunidades, permeável aos saberes originados da interlocução dos diferentes coletivos de pensamentos, pode contribuir para a transformação do ensino, aproximando-se do idealizado pelos jovens aprendizes. Como já discorrido anteriormente, a universidade deve promover a integração das atividades de ensino, pesquisa e extensão de acordo com as demandas de desenvolvimento local, almejando o pleno envolvimento da comunidade, para que ela possa produzir conhecimentos relacionados com a dinâmica da transformação social e responder aos reclames da comunidade regional e nacional (Saraiva, 2007). A realização do projeto de extensão Escola Dentro da Universidade intensifica a política de extensão universitária da EBMSP, refletindo o seu compromisso social com a comunidade. Este projeto atende à semântica de extensão universitária, possibilitando a elaboração da práxis de um conhecimento resultante da troca de saberes acadêmicos e populares, confrontados com a realidade brasileira, construída no envolvimento de todos os atores sociais, sejam do ensino médio, sejam do superior (Guimarães, Ferreira e Villaça, 2008).

Percebe-se que, por meio da participação e do auxílio aos governos, pode-se prestar serviços às classes mais carentes, integrando os alunos ao mundo das ciências e deixando-os preparados e motivados não só a ingressar no mundo científico como a se apropriar da escola como seu espaço, e utilizá-la para atividades científicas e educacionais que os enriqueçam e visem à mudança individual. A prática da educação para saúde contribui para a estruturação de pessoas íntegras e dignas que possam ser parceiras comprometidas com a educação e com a saúde. Abriu-se um novo horizonte para os envolvidos no projeto, na busca de informação para formação acadêmica e profissional por meio das atividades realizadas. 
Esse projeto de extensão universitária possibilitou o reconhecimento de alguns fatores responsáveis pelo ciclo de exclusão e oportunizou o acesso ao conhecimento. Isso reafirma a necessidade de se retomar a verdadeira essência da educação como bem coletivo e direito assegurado de todos os cidadãos. Por meio desses questionários e das informações levantadas, foi possível também avaliar algumas das necessidades básicas da educação pública brasileira. A universidade poderá ajudar a amenizar e a formar profissionais que diminuam ou entendam as diferenças sociais, construindo uma sociedade mais homogênea na apropriação de conhecimentos básicos, como defende o Plano Nacional de Extensão Universitária (Brasil, 2001).

As metodologias participativas utilizadas no planejamento das ações de extensão possibilitam a integração entre professores, estudantes e comunidade que compartilham e trocam saberes (Guimarães, Ferreira e Villaça, 2008). As oficinas, as enquetes e os jogos realizados no Dia de Saúde do Jovem foram recursos facilitadores do aprendizado desenvolvidos pelos estudantes de medicina integrantes do Nepe para aprimorar esse processo de aprendizagem, sendo modificados a cada encontro com a comunidade como reflexo da troca de saberes. Esses recursos foram elaborados a partir de um processo andragógico (ensino para adulto) que utiliza as informações prévias do estudante acerca de um tema para sedimentar o conhecimento. Dessa forma, o aluno do ensino médio se torna agente ativo no processo de aprendizagem e modificador indireto do material de aprendizado.

Os projetos de extensão contrariam a lógica da impessoalidade estabelecida em muitos setores da vida acadêmica, sendo um espaço de estabelecimento de relações solidárias, baseadas na afetividade e na instituição de vínculos de amizade nas relações sociais entre o acadêmico e a comunidade (Brasil, 2000/2001; Saraiva, 2007; Ribeiro, 2009). Para os estudantes de medicina integrantes do Nepe, a execução do projeto representou uma realização pessoal na busca dessas relações solidárias. O desenvolvimento de ferramentas pedagógicas possibilitou a introdução de alunos de ensino médio no conhecimento de ciências e permitiu a sua capacitação, incorrendo na quebra de um ciclo paradoxal de exclusão e transformação desses estudantes em agentes modificadores e incentivadores das possibilidades de construção e mudança social.

Observou-se que a articulação de pesquisa e extensão ao ensino foi fundamental para o desenvolvimento de competências na formação do graduando de medicina. Dessa forma, a extensão propicia outras ferramentas pedagógicas que conectam teoria e prática, no sentido de atender às Diretrizes Curriculares Nacionais instituídas pela resolução CNE/CES n. 4, de 7 de novembro de 2001 (Brasil, 2001). A realização do projeto Escola Dentro da Universidade possibilitou maior desenvolvimento do estudante de medicina no processo de humanização, assim como na capacidade crítica e reflexiva 
alicerçada em princípios éticos, objetivando o perfil do profissional que se almeja formar. Os resultados satisfatórios do projeto evidenciam a importância da extensão na educação médica, quando possibilita a aproximação dos universitários com a complexidade das interações sociais, promovendo a participação deles nos processos de conscientização sobre as mudanças sociais necessárias, assim como os tornam contribuintes efetivos na produção de conhecimento e sua difusão (Guimarães, Ferreira e Villaça, 2008).

Acredita-se que esse projeto estimulou a aproximação precoce de acadêmicos e docentes com as comunidades, aspecto que representa um dos caminhos apontados para a construção de vínculos e laços efetivos de humanização (Binz, Menezes Filho e Saupe, 2010). Dessa forma, o projeto Escola Dentro da Universidade agrega à formação acadêmica do graduando de medicina a possibilidade de união da teoria com a prática, na busca de transformação de valores e atitudes durante a graduação, contribuindo para práticas humanizadas na saúde.

\section{Conclusão}

Ao fim deste trabalho, foi possível concluir que o ensino superior privado pode participar da inclusão social, intervindo na comunidade, qualificando indivíduos para ingressarem no processo de formação profissional ou formando profissionais mais atentos à dinâmica social, de modo a assegurar a eficácia da equidade e da justiça como princípios básicos de uma sociedade. Em relação ao contato com a comunidade onde estão inseridos, os cinco alunos bolsistas relataram que aplicaram o conhecimento adquirido, informando e conscientizando as pessoas mais próximas quanto à prevenção de DSTs e da gravidez indesejada, tornando-os cidadãos multiplicadores do conhecimento. Reconceituar o seu papel ativo na educação e na prevenção em saúde, com participação efetiva de acadêmicos, cientistas e educadores, continua sendo um grande desafio para o ensino superior da área da saúde.

\section{Colaboradores}

Liliane Lins responsabilizou-se pela idealização do projeto, elaboração das oficinas, supervisão do projeto, coleta de dados, análise estatística, revisão de literatura e elaboração do manuscrito. Tanto Mayala Moura Valença de Oliveira como Ana Carolina Esteves Cattony fizeram coleta de dados, 
revisão de literatura e elaboração do manuscrito; Carla Reale Batista trabalhou na elaboração de oficinas, coleta de dados e revisão de literatura; Patrícia Dias Schmitz e Thaís de Lira Caracas fizeram coleta de dados e revisão de literatura; André Luiz Peixoto fez elaboração de oficinas, coleta de dados e revisão de literatura.

\section{Agradecimentos}

Agradecemos à Escola Bahiana de Medicina e Saúde Pública, pelo apoio financeiro e estrutural na realização do projeto; ao programa de bolsas de Iniciação Júnior CNPq/Fapesb; aos bolsistas de iniciação científica Júnior de 2005 a 2010: Bruno Bernardo Pereira Santos, Caíque Matos Santos Bispo, Daniel Lucas Dórea Borges, Deisiane Cerqueira Silva, Gabriela Amado Frutuoso, Jéssica Souza de Jesus, Laércio Inácio da Costa Filho, Luana Sales dos Santos, Maria Laura Aguiar de Santana e Mariana Nascimento Valverde Alonso.

Resumen La extensión universitaria en el proceso educativo permite la elaboración de la praxis y del conocimiento científico a través de acciones en la comunidad, generando un proceso sistemático de intercambio de conocimientos. Este estudio evaluó las intervenciones educativas de la educación superior privada en la enseñanza media pública aplicadas a las áreas de ciencias y prevención de la salud, realizadas entre febrero de 2005 y noviembre de 2008. La intervención capacitó a veinte estudiantes de la enseñanza media, y realizó el Día de la Salud del Joven, con la participación de 362 alumnos de Salvador, Brasil. Se rellenaron cuestionarios anónimos, antes y después de cada seminario y taller, con preguntas sobre el tema tratado en las actividades. Se puntualizó la importancia de la intervención de la enseñanza superior privada en la calificación de los estudiantes de la enseñanza media de la red pública. La enseñanza superior privada puede participar en la inclusión social, calificando a los individuos para que ingresen en el proceso de formación profesional de forma más atenta a la dinámica social. El gran reto para la enseñanza superior en el campo de la salud sigue siendo reconceptualizar su papel activo en la educación y en la salud preventiva, con la participación efectiva de académicos, científicos y educadores.

Palabras clave extensión; enseñanza pública; universidad; educación médica. 


\section{Notas}

1 Escola Bahiana de Medicina e Saúde Pública, Salvador, Bahia, Brasil.

Doutora em Patologia Humana pelo Centro de Pesquisa Gonçalo Moniz da Fundação Oswaldo Cruz.<lilianelinskusterer@bahiana.edu.br; liliane.lins@ufba.br>

Correspondência: Escola Bahiana de Medicina e Saúde Pública, Rua Frei Henrique, 8, Nazaré, CEP 40050-420, Salvador, Bahia, Brasil.

2 Graduanda de Medicina na Escola Bahiana de Medicina e Saúde Pública, Salvador, Bahia, Brasil.<mayalavalenca@hotmail.com>

3 Graduanda de Medicina na Escola Bahiana de Medicina e Saúde Pública, Salvador, Bahia, Brasil.<acecattony@yahoo.com.br>

4 Graduanda de Medicina na Escola Bahiana de Medicina e Saúde Pública, Salvador, Bahia, Brasil.<carlota_reale@hotmail.com>

5 Graduanda de Medicina na Escola Bahiana de Medicina e Saúde Pública, Salvador, Bahia, Brasil. <sfpatriciadias@hotmail.com>

6 Graduanda de Medicina na Escola Bahiana de Medicina e Saúde Pública, Salvador, Bahia, Brasil.<azpeixoto@gmail.com>

7 Graduanda de Medicina na Escola Bahiana de Medicina e Saúde Pública, Salvador, Bahia, Brasil.<thaiscaracas@yahoo.com.br>

\section{Referências}

ALMEIDA, Maria C. C. de et al. Uso de contracepção por adolescentes de escolas públicas na Bahia. Revista de Saúde Pública, São Paulo, v. 37, n. 5, p. 566-75, 2003.

BINZ, Mara C.; MENEZES FILHO, Eliezer W.; SAUPE, Rosita. Novas tendências, velhas atitudes: as distâncias entre valores humanísticos e inter-relações observadas em um espaço docente e assistencial. Revista Brasileira de Educação Médica, Rio de Janeiro, v. 34, n. 1, p. 28-42, 2010.

BRASIL. Ministério da Educação. Fórum de Pró-reitores de Extensão das Universidades Públicas Brasileiras e SESU. Plano Nacional de Extensão Universitária. Brasília: Ministério da Educação, 2000/2001. (Edição atualizada).
BRASIL. Resolução CNE/CES n. 4, de 7 de novembro de 2001. Institui Diretrizes Curriculares Nacionais do Curso de Graduação em Medicina. Diário Oficial da União, Poder Executivo, Brasília, DF, 9 nov. 2001. Seção 1, p. 38.

BRÊTAS, José R. S. et al. Conhecimento sobre DST/AIDS por estudantes adolescentes. Revista de Escola de Enfermagem da USP, São Paulo, v. 43, n. 3, p. 551-557, 2009.

FERREIRA, Cristina A. O papel da educação em ciências e tecnologia no Brasil: um debate. Ciência e Cultura, São Paulo, v. 54, n. 4, p. 28-30, 2005.

GUIMARÃES, Regina Guedes Moreira; FERREIRA, Maria do Carmo; VILLAÇA, Fabiana 
de Mello. O debate necessário: a importância da extensão universitária para a formação médica. Cadernos ABEM, Rio de Janeiro, v. 4, p. 69-78, 2008.

MARTINS, Laura B. M. et al. Fatores associados ao uso de preservativo masculino e ao conhecimento sobre DST/AIDS em adolescentes de escolas públicas e privadas do Município de São Paulo, Brasil. Cadernos de Saúde Pública, Rio de Janeiro, v. 22, n. 2, p. 315-323, 2006.

PONTE, Cynthia I. R. V. et al. A extensão universitária na Famed/UFRGS: cenário de formação profissional. Revista Brasileira Educação Médica, Rio de Janeiro, v. 33, n. 4, p. 527-534, 2009.

RIBEIRO, Kátia S. Q. S. A experiência na extensão popular e a formação acadêmica em fisioterapia. Caderno Cedes, Campinas, v. 29, n. 79 , p. 335-346, 2009.
SARAIVA, José L. Papel da extensão universitária na formação de estudantes e professores. Brasília Médica, Brasília, v. 44, n. 3, p. 220-225, 2007.

SOUSA, Ana L. L. et al. Programa de Socialização das Tecnologias da Informação e Comunicação. In: CONGRESSO BRASILEIRO DE EXTENSÃO UNIVERSITÁRIA, 2., 2004, Belo Horizonte. Anais... Belo Horizonte, 2004.

SOUSA, José Nilton et al. Universidade e o Pré-Vestibular Popular. In: CONGRESSO BRASILEIRO DE EXTENSÃO UNVERSITÁRIA, 2., 2004, Belo Horizonte. Anais... Belo Horizonte, 2004.

Recebido em 06/09/2011

Aprovado em 20/01/2014 